\title{
Targeting B Cells to Modify MS, NMOSD, and MOGAD
}

\section{Part 1}

Jonas Graf, MD, Jan Mares, MD, Michael Barnett, MD, PhD, Orhan Aktas, MD, Philipp Albrecht, MD, Scott S. Zamvil, MD, PhD, and Hans-Peter Hartung, MD, FRCP

Neurol Neuroimmunol Neuroinflamm 2021;8:e918. doi:10.1212/NXI.0000000000000918

\section{Abstract}

Ocrelizumab, rituximab, ofatumumab, ublituximab, inebilizumab, and evobrutinib are immunotherapies that target various B cell-related proteins. Most of these treatments have proven efficacy in relapsing and progressive forms of MS and neuromyelitis optica spectrum disease (NMOSD), or are in advanced stages of clinical development. Currently, ocrelizumab, ofatumumab, and inebilizumab are licensed for treatment of MS and NMOSD, respectively. This review focuses on the current state of knowledge about the role of B lymphocytes in immunemediated pathophysiology and its implications for the mode of action. To understand the significance of this breakthrough in the context of the current MS therapeutic armamentarium, this review more closely examines the clinical development of CD20 depletion and the pioneering contribution of rituximab. Phase 3 and the recently published postmarketing studies will be highlighted to better understand the relevant efficacy data and safety aspects of longterm B-cell depletion.

\author{
Correspondence \\ Dr. Hartung \\ hans-peter.hartung@ \\ uni-duesseldorf.de
}

\section{RELATED ARTICLE}

Targeting B Cells to Modify MS, NMOSD, and MOGAD: Part 2

Page e919 


\section{Glossary}

BTK = Bruton tyrosine kinase; IgG = immunoglobulin G; IL = interleukin; MOG = myelin oligodendrocyte glycoprotein; NEDA = no evidence of disease activity; NMOSD = neuromyelitis optica spectrum disease; PPMS = primary progressive MS; RRMS $=$ relapsing-remitting MS; TNF $=$ tumor necrosis factor.

MS is the most common immune-mediated, chronic inflammatory disease of the CNS, affecting approximately 2.5 million individuals worldwide. The course of the disease is either relapsing-remitting or progressive. ${ }^{1,2}$ Although the precise triggers for this disease are not clear, evidence indicates that the pathogenesis is multifactorial and includes genetic, immunologic, and environmental factors. There is no cure for MS to date. The past 2 to 3 decades have nonetheless been characterized by the encouraging development of a great number of immunomodulatory treatment modalities. ${ }^{1,3,4}$ Particularly noteworthy among these is the introduction of the CD20 B cell-depleting monoclonal antibody rituximab and subsequently its humanized version ocrelizumab. ${ }^{5,6}$

Neuromyelitis optica spectrum disease (NMOSD) is a less frequent inflammatory disease, primarily affecting the optic nerve(s) and the spinal cord, that is caused by pathogenic immunoglobulin $\mathrm{G}(\mathrm{IgG})$ antibodies directed at the astrocytic endfoot aquaporin 4 water channel, which is made up of 6 transmembrane helical domains. ${ }^{7}$ Here, evidence-based therapies have recently taken center stage. The pathologic differences between MS and NMOSD have been concisely reviewed. ${ }^{8}$ NMOSD must be distinguished from myelin oligodendrocyte glycoprotein (MOG)-IgGrelated disease that features perivenous inflammation and white matter demyelination. $^{9-16}$

The prevalence of NMOSD among Whites globally is $1 /$ 100,000 , with an annual incidence of less than $1 /$ million. In Asians, the prevalence is $3.5 / 100,000$. The annual incidence of MOGAD in adults has been estimated to be 1.3 /million, in children $3.1 /$ million. $^{17}$

The purpose of this review is to provide a better understanding of the pathophysiologic role of B cells and their activity in MS and related disorders and to dissect the mechanisms by which B-cell modulation and depletion exert therapeutic effect in CNS disease. ${ }^{18,19}$ Treatment trials with B cell-targeted approaches are detailed. Benefits of this interventional strategy are weighed against known risks.

\section{B cell-driven immune responses underlying MS, NMOSD, and MOGAD}

\section{Proof of principle: rituximab}

The critical role of $\mathrm{B}$ cells in $\mathrm{MS}^{20}$ and $\mathrm{NMOSD}^{21}$ was recently reviewed. It was the demonstration that rituximab is highly effective in MS that prompted a reappreciation of the contributions of B cells to MS pathogenesis (figure 1).

In the first case report of a patient with aggressive relapsing MS disease stabilized with rituximab, B cells were depleted in CSF and peripheral blood. ${ }^{22} \mathrm{~B}$-cell counts in patients with primary progressive MS were lowered more in peripheral blood than in $\mathrm{CSF}^{23}$ In a phase 2 trial of patients with relapsing-remitting MS (RRMS) receiving rituximab as add-on therapy, decreases of both B- and T-lymphocyte counts were observed in CSF. ${ }^{24}$ Several case reports convincingly demonstrated that rituximab not only mitigated or arrested progression of a fulminant disease course but also led to clinical improvement. ${ }^{22,25,26}$

The beneficial effects of B-cell depletion in NMOSD were first demonstrated in an open-label study of rituximab, published in $2005,{ }^{27}$ followed by a retrospective analysis of 25 patients with NMOSD in $2008^{28}$ and a prospective long-term cohort study of 10 patients. ${ }^{29}$

\section{MS}

\section{Mode of action of CD20 cell depletion in MS-evidence emphasizing the role of B cells in MS pathogenesis}

\section{Binding of monoclonal antibodies to CD20}

$\mathrm{CD} 20$ is a member of the membrane-spanning $4 \mathrm{~A}$ gene family encoded by the MS4A1 gene on chromosome $11 .^{30}$ The CD20targeting monoclonal antibodies recognize shared or slightly different epitopes. Ublituximab (TG-1101) binds to a unique part of the CD20 domain ${ }^{31,32}$ (figure 2). Recent work suggests a double-barrier dimer structure. ${ }^{33}$ In general, binding of these antibodies induces the redistribution of CD20 into lipid rafts within the plasma membrane and may thus disrupt B-cell receptor signaling. Because of amino acid mutations in the $\mathrm{Fc}$ portion, rituximab and ofatumumab bind $\mathrm{C} 1 \mathrm{q}$ more avidly than ocrelizumab and lead to complement activation and complement-dependent cytotoxicity. In contrast, ocrelizumab more potently promotes antibody-dependent cellular cytotoxicity and phagocytosis via its interaction of $\mathrm{Fc} \gamma$ receptors on natural killer cells, monocytes, macrophages, and neutrophils. ${ }^{34,35}$ Based on these differential properties, anti-CD20 antibodies are termed type I (rituximab and ofatumumab) or type II (ocrelizumab). ${ }^{36,37}$

CD20 cell depletion had not only a therapeutic effect on RMS or RRMS but also, for the first time, on the primary progressive course of the disease (PPMS). ${ }^{38,39}$ In the first trial 


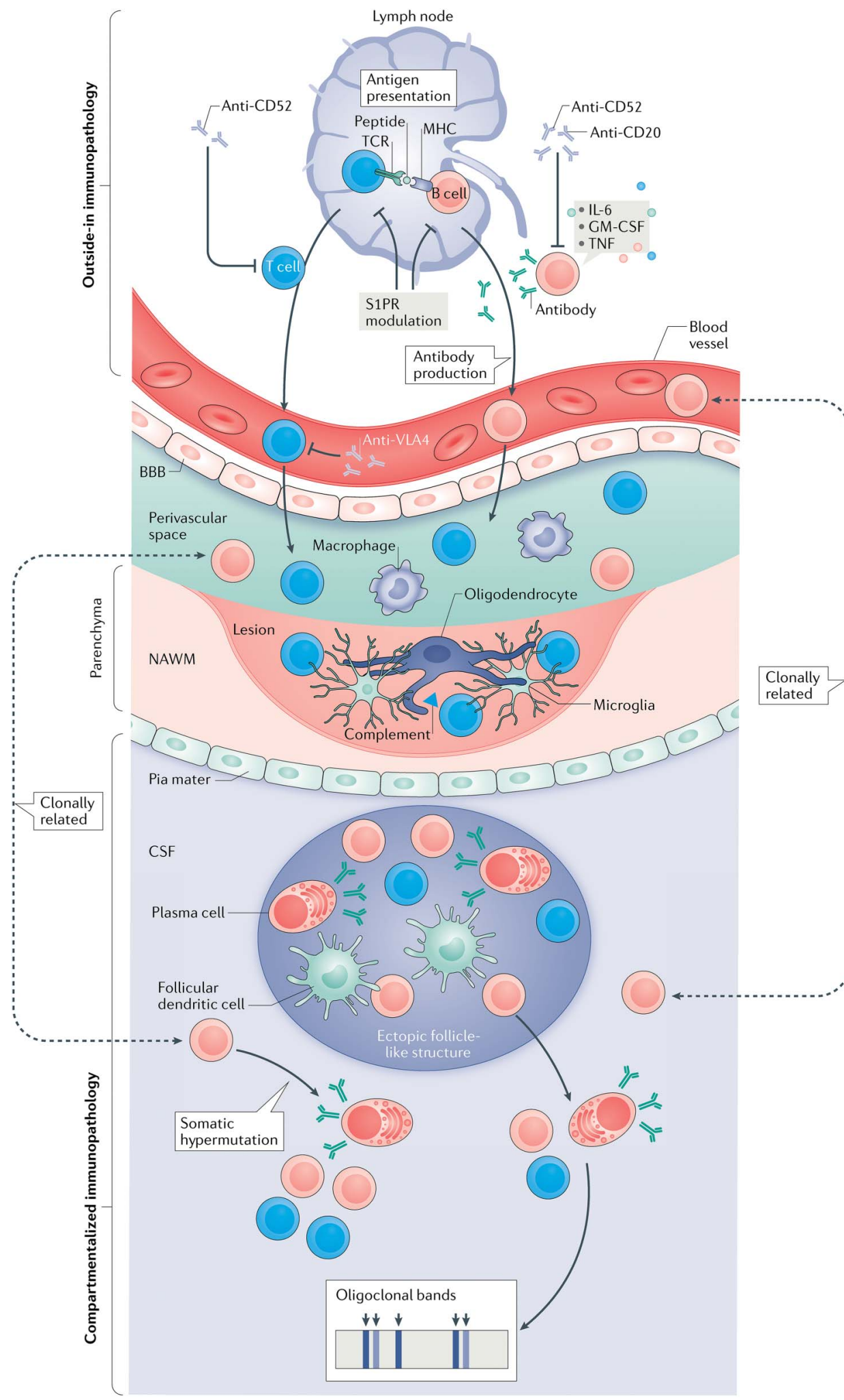

$B$ and $T$ cells in the peripheral lymphoid tissues reciprocally activate each other. They migrate to the CNS passing through the blood-brain barrier. Most $B$ cells locate to the perivascular space. Aggregates of B lymphocytes are observed in the pia mater overlying the cortex. In secondary progressive MS, a compartmentalized inflammation in an ectopic follicle-like lymphoid tissue is driven by $B$ cells, plasma cells, $T$ cells, and follicular dendritic cells. In the CSF, antibody-producing memory B cells, plasmablasts, and plasma cells give rise to oligoclonal bands. From ref. 18 with permission by Springer Nature.

using rituximab in PPMS, the primary end point was not reached. However, when stratified to subsets, the group (1) $<50$ years and (2) Gd + did better statistically than placebo. ${ }^{38}$
One of the most fascinating aspects of CD20 depletion in MS is that although the target cell is known, it remains unclear which intercepted B-cell function is most relevant in this context. B cells may contribute to autoimmune disease via 
Figure 2 Epitopes on CD20 recognized by anti-CD20 monoclonal antibodies

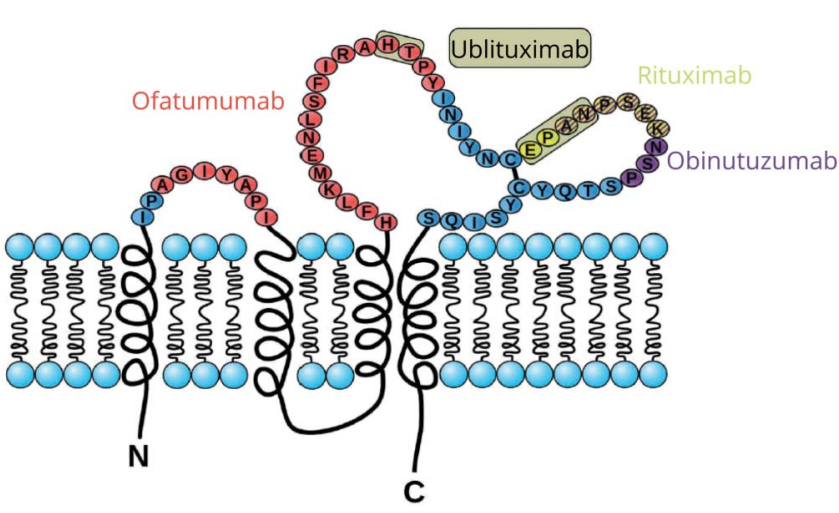

CD20-targeted monoclonal antibodies recognize epitopes either identical or spatially in close neighborhood. Only ublituximab binds to a unique epitope on the CD20 domain. From ref. 31 with permission by SAGE Publishers.

autoantibody-dependent and autoantibody-independent functions. . $^{40,41}$

Figure 3 illustrates the specific B-cell developmental stages targeted by a therapy directed against the CD20 differentiation antigen. This is an effective therapeutic approach, which clearly underpins the current clinical developments and recent approvals granted to subsequent preparations with similar activity profiles (e.g., evobrutinib ${ }^{42}$ NCT04032158, ofatumumab $^{43}$ NCT02792218 or NCT02792231, ublituximab NCT03277261 or NCT03277248, and NCT04032171). Furthermore, the development of rituximab biosimilars like obinituzumab is in progress to reduce drug resistance. ${ }^{44} \mathrm{It}$ is interesting to note that low-dose intrathecal administration of rituximab leads to complete depletion of CD20 in peripheral blood ${ }^{45}$ but not to complete CD20 depletion in the CNS. ${ }^{46}$

\section{CD20-depleting antibodies and the role of B cells in MS}

These therapeutic developments have contributed to a major revision of our understanding of the pathophysiologic role of immune cells in MS. ${ }^{47}$ It is currently widely accepted that B cells - and not exclusively or predominantly T cells — play a central role in MS (figure 1, e-figure 1, links.lww.com/NXI/ A345). Table 1 summarizes the evidence invoking a key pathophysiologic role of B cells in MS.

Initially, B-cell depletion was expected to exert its effect by diminishing the production of autoantibodies (e-figure 1, links.lww.com/NXI/A345). However, the rapid onset of the profound effects of CD20 B cell-targeted therapies has prompted a reevaluation of the humoral immune response in MS. The concept holds that clinical benefit preceded humoral change/autoantibody synthesis. This ties to the cellular effect of B-cell depletion-e.g., B- and -T lymphocyte collaboration with decreased Th17 and Th1 cytokine production. ${ }^{48,49}$

The precise mechanisms underpinning the efficacy of CD20 cell depletion in MS and its animal models remain incompletely understood. ${ }^{47,50-55}$ The interaction of specifically $\mathrm{B}$ and $\mathrm{T}$ cells may be particularly relevant to $\mathrm{MS}$ pathology. ${ }^{56}$ The effectiveness of B-cell depletion in MS has been invoked to support the hypothesis that B cells latently infected with Epstein-Barr virus may play an important role in the pathogenesis of MS. ${ }^{57,58}$ Animal studies have indicated that CD20 depletion modulates activation of monocytes and microglia

Figure 3 Cellular targets of CD19 and CD20 cell depletion therapies

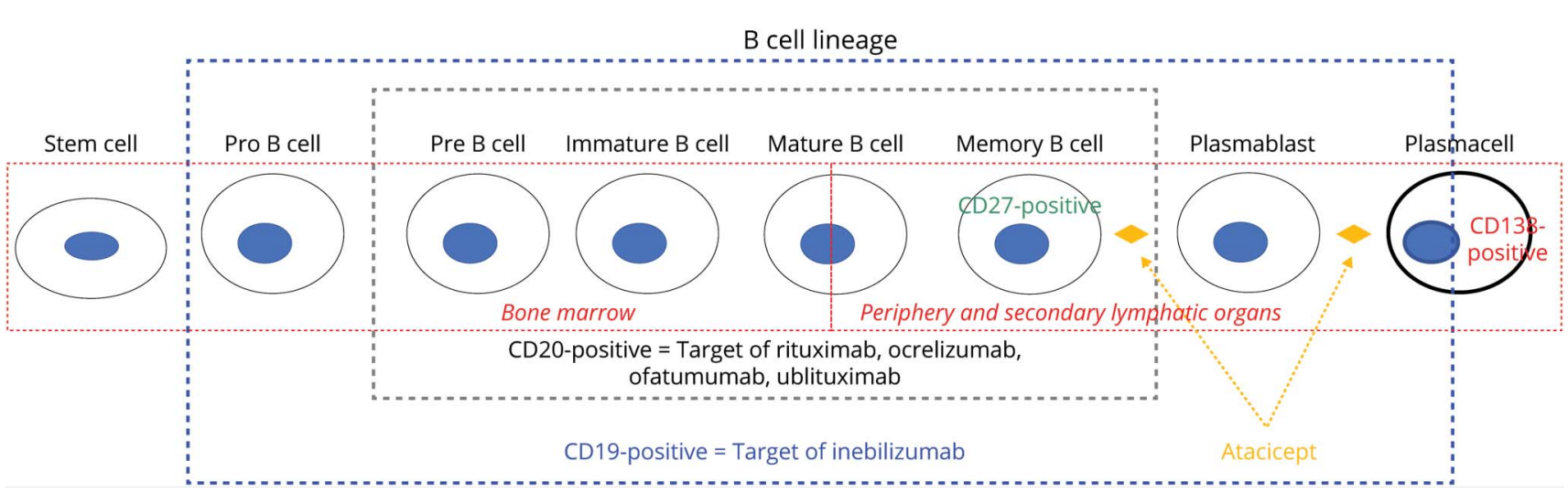

A number of differentiation antigens are expressed on the cell surface during B-cell maturation and are subsequently recognized by the respective monoclonal antibodies used during therapy. Monoclonal antibody/antigen binding ultimately leads to depletion via antibody mediated or complementdependent cytotoxic mechanisms. It is important that both early and late maturation stages are not depleted because they do not express CD19 or CD20. This means that the ability to repopulate $B$ cells is preserved and humoral immune memory is not impaired. This maintains the function of natural defense mechanisms. CD19 in contrast to CD20 is expressed also on pro-B cells and plasma cells. Thus, CD19-directed monoclonal antibodies have a broader coverage of the B-cell lineage. A minor subpopulation of CD3 T lymphocytes, CD8 more than CD4 T cells, also display the CD20 antigen. They have been shown to be depleted following rituximab administration. ${ }^{\mathrm{e} 25} \mathrm{It}$ is controversial whether they are increased in activity exhibiting higher proinflammatory potential in blood and CSF of people with MS compared with healthy individuals. CD20-depleting therapy removes myelin-reactive CD8 T lymphocytes from the circulation of patients with MS. ${ }^{\text {33 }}$ 
Table 1 Evidence for potential pathophysiologic functions of B lymphocytes in MS

Synthesis of intrathecal oligoclonal bands

Production of antibodies against myelin components in blood and CSF

B-cell accumulation and activated complement deposition in brain lesions

Meningeal B-cell aggregates in SPMS

Increased number of plasmablasts in blood and CSF

Antigen presentation, cytokine production, stimulation, and regulation of autoreactive proinflammatory T cells

Induction and regulation of the proliferation of autoreactive, proinflammatory T cells (including TH17 cells) homing to the CNS

Induction of neuronal apoptosis and oligodendroglial cytotoxicity

Abbreviation: SPMS = secondary progressive MS

and the recruitment of T lymphocytes. ${ }^{49,59}$ Pathogenic CD40mediated NF- $\mathrm{KB}$ activation of $\mathrm{B}$ cells is increased in patients with MS. ${ }^{60}$ In addition, the significance of B-cell aggregates in lymphoid follicle-like structures of the subarachnoid space, particularly in patients with secondary progressive forms of the disease, is the subject of intense discussion. ${ }^{\mathrm{e}}{ }^{1, \mathrm{e} 2}$ An animal study demonstrated that an intrathecal administration of antiCD20 antibodies induces significant B-cell depletion in established CNS lesions. ${ }^{\text {e3 }}$

There is also evidence of direct crosstalk between the CNS and the periphery in patients with MS, which is notably mediated by class-switched immunoactive $\mathrm{B}$ cells, ${ }^{\mathrm{e} 4}$ in conjunction with the observation that $B$ cells of patients with MS exhibit augmented antigen-presenting properties $^{\mathrm{e} 5}$ (figure 1). These lymphocytes must overcome several immune barriers via complex cascades ${ }^{\mathrm{e} 6}$ to enable clonal expansion, ${ }^{\mathrm{e} 7}$ produce specific immunoglobulins, ${ }^{\mathrm{e} 8}$ and promote lymphangiogenesis. ${ }^{\mathrm{e} 9}$ It is currently understood that the maturation of CNS B cells of patients with MS occurs in the draining cervical lymph nodes. ${ }^{\text {e10 }}$ B cells of patients with RMS are able to manufacture complement- and immunoglobulin-independent factors that are toxic to neurons and oligodendrocytes in vitro. $^{\text {e11,e } 12}$ Patients with myelitis as the sole clinical manifestation, who are therefore potentially at an early stage of MS, were found to have an expanded and mutated plasmablast subgroup ${ }^{\mathrm{e} 13}$ and a specific distribution of interleukin-6/-10-producing B lymphocytes, ${ }^{\text {e14 }}$ consistent with our current understanding of cytokine function in autoimmune diseases. ${ }^{\text {e15 }}$ It would therefore appear that $B$ cells assume an important role both at the onset and during the perpetuation of $\mathrm{MS}^{\mathrm{e}}{ }^{\mathrm{e} 6}$ Regulation of the macrophage migration inhibitory factor pathway appears to be pertinent as CD74 deficiency and upregulation of CXCR4 are associated with early MS. ${ }^{\text {e17 }}$

However, not all B lymphocytes are considered to be pathophysiologically significant, but rather restricted subgroups of B cells only. Proinflammatory cells, particularly $\mathrm{CD} 27^{+}$ memory B cells, can act as antigen presenters and manufacture tumor necrosis factor (TNF) alpha, interleukin (IL)-6, and granulocyte-macrophage colony stimulating factor, with IL-6 being a driver of pathogenic Th17 T-cell responses. Anti-inflammatory regulatory B cells (Bregs) release IL-10, TGFß, and IL-35 ${ }^{\text {e18-e20 }}$ and other specific B-lymphocyte subgroups present in CSF that may be primary determinants of disease phenotype. ${ }^{\mathrm{e} 21}$

Based on the observations of MS phase-dependent surface expression of differentiation antigens during $\mathrm{B}$-cell maturation and the results of the recently completed phase $2 / 3$ trial of inebilizumab, a monoclonal antibody directed against $\mathrm{CD} 19^{\mathrm{e} 22}$, a distinction must be made between $\mathrm{CD} 20$ and CD19 depletion in NMOSD (figure 3). CD20 is not expressed on the surface of plasma cells nor pro-B cells, whereas CD19 can be detected on the majority of plasma cells in secondary lymphatic organs (e.g., spleen and tonsils), on all blood plasma cells, and in more than $50 \%$ of bone marrow plasma cells. ${ }^{\text {e23,e24 }} \mathrm{CD} 19^{+} \mathrm{B}$ cells can also still express MHC II (i.e., human leukocyte antigen-DR); thus, anti-CD19 eliminates residual APC function, whereas anti-CD20 does not. ${ }^{18}$

It should be noted that in contrast to CD19, CD20 is expressed also by a subgroup of $\mathrm{CD} 3$-positive $\mathrm{T}$ cells. ${ }^{\text {e25 }}$ These CD20 CD3 T cells have been shown to be depleted following rituximab administration. It is controversial whether they are increased in activity exhibiting higher proinflammatory potential in blood and CSF of people with MS compared with healthy individuals.

In summary, B cells are not exclusively responsible for the development and perpetuation of MS. There is evidence supporting the notion that (memory) B cells induce autoreactive, autoproliferative, ${ }^{\mathrm{e} 26}$ proinflammatory $\mathrm{T}$ cells (including $\mathrm{T}_{\mathrm{H}} 17$ cells), which in turn play a crucial role in CNS inflammatory cascades ${ }^{\mathrm{e} 27-\mathrm{e} 29}$ and that polymorphonuclear myeloid-derived suppressor cells selectively control the accumulation of B cells in the CNS ${ }^{\text {e30 }}$ Nevertheless, to date, the specific target antigen(s) of these immune cells remains to be identified. ${ }^{\text {e31 }}$ The role played by CD20-positive CD3 T cells, a small subgroup of $\mathrm{T}$ cells, in MS also remains to be defined. ${ }^{\mathrm{e} 2}$ 
One study suggests that they comprise myelin-reactive CD8 T cells. ${ }^{\text {e33 }}$

\section{Rituximab in MS}

A phase 1 trial evaluating 26 patients with RRMS, in the absence of a control group, demonstrated a good 72-week rituximab safety profile and showed that rituximab reduced the development of new lesions between week 4 and week 72 , as well as flare-ups, compared with the year preceding the treatment. $^{\text {e34 }}$ The double-blind, placebo-controlled phase 2 trial (Helping to Evaluate Rituxan in Relapsing-Remitting Multiple Sclerosis [HERMES], e-table 1, links.lww.com/ NXI/A346) additionally confirmed that rituximab 1,000 mg administered on days 1 and 15 was more effective than placebo, not only in terms of the primary MRI end points but also for all secondary clinical end points examined. ${ }^{\text {e35 }}$ Pharmacodynamically, rituximab was associated with rapid almost complete depletion of $\mathrm{CD} 19^{+} \mathrm{B}$ cells from weeks 2 to 24 . By week 48 , CD 19 cells had returned to $31 \%$ of baseline. ${ }^{\text {e35 }}$ B-cell depletion resulted in markedly diminished proinflammatory Th1 and Th17 responses of CD4 and CD8 T lymphocytes. ${ }^{48}$

Given the surprisingly good efficacy of CD20 cell depletion in patients with RRMS, it was hoped that this therapeutic approach might also prove to be effective in the primary progressive course of the disease. To this end, a randomized, double-blind, placebo-controlled phase 2/3 trial was conducted in patients with PPMS (OLYMPUS, e-table 1, links. lww.com/NXI/A346). Four hundred thirty-nine patients received $21,000 \mathrm{mg}$ rituximab or placebo infusions every 24 weeks until week 96. This trial failed to meet the clinical primary end point, as there was no significant difference in confirmed disease progression. Despite this disappointing result, expectations for rituximab's efficacy remained, as the secondary radiologic end point of $\mathrm{T} 2$ lesion load was met and post hoc subgroup analyses indicated that younger patients (less than 50 years of age) with active inflammatory lesions, in particular, seemed to benefit from rituximab treatment. ${ }^{38, \mathrm{e} 36}$

Furthermore, several retrospective analyses and a subgroup analysis provided evidence that rituximab can be effective both in aggressive RMS and progressive $\mathrm{MS}^{\mathrm{e} 37-\mathrm{e} 43}$ and that it is also more effective than first-generation MS treatments (i.e., interferon-beta and glatiramer acetate). ${ }^{44, e 45}$ In the large Swedish study, doses of rituximab above $750 \mathrm{mg} / 6$ months were not more effective than those below. ${ }^{\mathrm{e} 33}$ A retrospective Swiss study of 37 patients with RRMS and 22 patients with SPMS observed that lowering rituximab from $1,000 \mathrm{mg}$ to 500 $\mathrm{mg} / 6$ months was safe and produced clinical and MRI stability. It also left serum neurofilament light chain levels unaffected. The authors suggested that with a lower dose one might avoid more marked hypogammaglobulinemia and thereby the risk of infectious complications ${ }^{\mathrm{e}}{ }^{46}$

\section{Ocrelizumab: breakthrough in MS therapy}

Subsequent studies, investigating the efficacy of CD20 depletion in patients with MS, used the humanized equivalent ocrelizumab instead of the chimeric monoclonal antibody rituximab (table 3). Ocrelizumab was administered initially in 2 induction doses of $300 \mathrm{mg}$ IV at a 14-day interval, followed by a dose of $600 \mathrm{mg}$ IV every 6 months over the course of the trial. In the initial randomized, double-blind, placebo-controlled phase 2 trial in RMS with a double-dummy design, interferon beta-1a administered IM served as the active comparator in RMS. Ocrelizumab was shown to be more effective than placebo and the active comparator in terms of the radiologically defined primary end point (number of gadolinium-positive T1 lesions in brain MRI). No significant differences were identified between individual groups in terms of side effects. ${ }^{\text {e47 }}$

Subsequent phase 3 trials led to the approval of ocrelizumab for the treatment of RMS and PPMS. ${ }^{\text {e48 }}$ Both ocrelizumab vs IM interferon beta-1a in RMS (OPERA I and II) ${ }^{\text {e49 }}$ and ocrelizumab vs placebo in early PPMS (A Study of Ocrelizumab in Participants With Primary Progressive Multiple Sclerosis [ORATORIO] $)^{39}$ met the defined clinical primary end points. The RMS twin studies achieved the primary end point, which was defined as the annualized relapse rate, with an absolute risk reduction of $46 \%$ and $47 \%$, respectively. All secondary end points were also met with the exception of the percentage change in brain volume in the OPERA II trial.

Following the double-blind phase, patients from both OPERA studies were maintained on ocrelizumab or switched from interferon- $\beta$ 1a for 3 years when clinical and MR outcomes and safety were assessed. Pooled analysis of the $88.6 \%$ of patients that completed 5 years showed maintenance of clinical (annualized relapse rate, 24-week confirmed disability progression and improvement) and MRI effects (total number of new or newly enlarged T2 lesions and T1 gadoliniumenhancing lesions assessed every 48 weeks).

Patients on continuous ocrelizumab treatment from beginning fared better than those with delayed treatment onset. Whole, gray and white matter brain volume loss was less marked in the group on continuous vs delayed treatment. No new safety signals emerged. ${ }^{\text {e50 }}$

In the double-blind period, NEDA (no evidence of clinical or MRI disease activity) was attained in $48.5 \%$ of the ocrelizumab and $27.8 \%$ in the IFNB-1a-treated patients. During the openlabel extension, the proportion of patients with NEDA was $65.4 \%$ in patients continuously receiving ocrelizumab vs $55.1 \%$ in the switching population. ${ }^{\text {e51 }}$

In the PPMS trial, both the primary end point (disease progression confirmed after 12 weeks) and the secondary MRI end points were met. After 120 weeks, $32.9 \%$ of patients in the ocrelizumab and $39.3 \%$ in the placebo group had progressed (relative risk reduction of $24 \%$ ), whereas absolute brain lesion volume decreased by $3.4 \%$ (ocrelizumab) and 7.4\% (placebo), respectively. A recent post hoc analysis confirmed an improvement in arm function using the 9 Hole Peg Test. The proportion of patients with confirmed deterioration in the 9 
Hole Peg Test was also lower in the ocrelizumab treatment group. ${ }^{\text {e52 }}$ A retrospective analysis of a large multicenter MS cohort revealed that $5 \%$ of all patients experienced confirmed disease progression, whereas the annualized relapse rate was 0.17 . $^{\mathrm{e} 53}$

It is noteworthy that the PPMS trial patterned on the results of the phase 2 OLYMPUS trial of rituximab only included patients who had a relatively short duration of the disease, as defined by age (18-55 years) and symptoms $<15$ years in patients with an expanded disability status score of $>5.0$ or $<10$ years in those with an expanded disability status score of $<5.0$ at the time of screening. Both acute infusion reactions and respiratory tract and oral herpes infections emerged as significant adverse events. There was also a trend toward an increased risk of cancer (particularly of breast cancer) ( $2.3 \%$ vs $0.8 \%$ ), although extended follow-up and postmarketing experience did not confirm this association. Besides, the incidence was in the range expected in the general population. ${ }^{\text {e54,e55 }}$

Repletion of B cells appears not to be uniform. A recent study of 74 patients with MS noted $41.8 \%$ who had their CD19 cells returning at 6 months, the so-called fast responders. Twentyfour percent had CD19 cells above $2 \%$. Fast response was associated with a higher body mass index. ${ }^{\mathrm{e} 56}$

B-cell repopulation has been associated with a rise in the relapse rate in the case of NMOSD, a relapsing-remitting chronic inflammatory CNS disease with concomitant astrocytopathy. ${ }^{e 57}$ In this context, CD19/CD27-positive $B$ cells seem to be especially important. ${ }^{\text {e58 }}$ It remains unclear to what extent this correlation can be extrapolated to RMS. In the pivotal clinical trials, $20.7 \%$ of patients with RMS and $26.3 \%$ of patients with PPMS experienced a decrease in absolute lymphocyte counts below the lower limit of normal. ${ }^{\text {e59 }}$ The majority of patients developed grade 1 or 2 lymphopenia, the incidence of grade 3 lymphopenia was $1 \%$, and no CD19-positive cells could be detected in peripheral blood as early as 2 weeks after the start of the treatment. ${ }^{42, \mathrm{e} 49}$ The lymphocyte population was restored in $90 \%$ of the patients, after a 2.5 -year (median 72 weeks) ocrelizumab treatment pause. ${ }^{\text {e59 }}$ In comparison, the lymphocyte population in the rituximab phase $2 / 3$ trial (OLYMPUS) was restored in $35 \%$ of the patients, 48 weeks after discontinuing treatment. ${ }^{38}$ Results from the surveillance studies after marketing authorization was granted in January $2018^{\mathrm{e} 59}$ (for indications, refer to e-table 2, links.lww.com/NXI/A346) confirmed the benefits of ocrelizumab. Of note, $66.4 \%$ of patients with RMS receiving ocrelizumab vs $24.3 \%$ of interferon beta- 1 a patients exhibited no evidence of clinical or radiologic disease activity (NEDA). ${ }^{60}$ In the absence of direct comparative studies evaluating ocrelizumab against other MS therapies, a meta-analysis performed showed that ocrelizumab is a viable treatment option, particularly for patients with highly active RMS. ${ }^{\text {e61 }}$ Furthermore, several retrospective analyses and a subgroup analysis provided evidence that rituximab can be effective both in aggressive RMS and progressive $\mathrm{MS}^{\mathrm{e} 37-\mathrm{e} 43}$ and that it is also more effective than first-generation MS treatments (i.e., interferon beta and glatiramer acetate). ${ }^{\text {44,e45 }}$ To better characterize the response of patients with PPMS to immunotherapy, the composite outcome termed NEPAD—no evidence of progression or active disease-has recently been introduced. Operationally, it is defined as absence of 12week confirmed disability progression; absence of 12 -week confirmed progression of $\geq 20 \%$ on the Timed 25 -Foot Walk test and 9-Hole Peg Test; no brain MRI activity (no new/enlarging $\mathrm{T} 2$ lesions and no $\mathrm{T} 1$ gadoliniumenhancing lesions); and no protocol-defined relapses. ${ }^{\text {e58 }}$ In the ORATORIO trial, ocrelizumab tripled the proportion of patients with PPMS with NEPAD after 120 weeks compared with placebo. ${ }^{\text {e62 }}$ An analysis of pooled phase 2 and 3 data suggests that ocrelizumab effectively suppresses disease activity detected by MRI within 4 weeks and suppresses clinical disease activity within 8 weeks. ${ }^{\text {e63 }} \mathrm{A}$ post hoc study suggests that ocrelizumab is also effective in patients with MS with increased baseline disability. ${ }^{\text {664 }}$ An MR spectroscopy study taking sequential measurements of markers of neuronal-myelin coupling over a 96-week period demonstrated that ocrelizumab reduces cerebral gliosis compared with patients who received interferonbeta. $^{\text {e65 }}$ It also appears that progression in patients with PPMS is associated with chronic lesion activity in the white matter. ${ }^{\text {e66 }}$ Currently, multiple phase $3 \mathrm{~b}$ studies are being performed to better characterize ocrelizumab in MS (table 2). ORATORIO HAND (NCT04035005) explores its effect on the function of the upper extremity in PPMS, CONSONANCE (NCT03523858) monitors disease activity in PPMS, and CHORDS (NCT02637856) and CASTING (NCT02861014) scrutinize safety and efficacy in RRMS after suboptimal response to a different DMT.

ENSEMBLE (NCT03085810) examines the effect of ocrelizumab in people with early RMS. A recently published study (ENSEMBLE PLUS) showed that shorter infusion times were well tolerated and not associated with more adverse events. $^{\text {e67 }}$

A phase III b open-label study, VELOCE (NCT00676715), evaluated the effectiveness of common vaccinations in patients with relapsing MS treated with ocrelizumab. Responses to clinically relevant antigens (tetanus toxoid, pneumococcal antigens, and influenza or keyhole limpet hemocyanin as a neoantigen) were elicited but attenuated compared with controls on interferon- $\beta$ or no disease-modifying drug. ${ }^{\text {e68 }}$ OBOE (NCT02688985) investigates immunologic changes occurring during ocrelizumab treatment.

In the absence of a phase 3 trial, the issue of whether rituximab is an equivalent alternative to ocrelizumab remains open to debate. ${ }^{\text {e69-e72 }}$ Direct comparative studies between rituximab and other treatment options would be helpful to close the gaps in our current understanding. ${ }^{\mathrm{e} 73}$ 
Table 2 Ocrelizumab phase 2 and 3 trials for the treatment of MS

\begin{tabular}{|c|c|c|}
\hline Trial & $\begin{array}{l}\text { Primary end point } \\
\text { Result }\end{array}$ & $\begin{array}{l}\text { Secondary end point } \\
\text { Result }\end{array}$ \\
\hline $\begin{array}{l}\text { Phase } 2 \text { RRMS } \\
\text { Kappos et al. } 2011 \\
\text { Lancet } \\
\mathrm{n}=220 \\
1: 1: 1 \text { randomization to placebo, } 600 \mathrm{mg} \text { or } \\
2000 \mathrm{mg} \text { ocrelizumab IV at days } 1 \text { and } 15 \text { or } \\
\text { IFNß1a } 30 \mu \mathrm{g} \text { IM. } \\
\text { At week } 24 \text {, all received ocrelizumab. }\end{array}$ & $\begin{array}{l}\text { - Number of gadolinium- } \\
\text { positive T1 lesions between } \\
\text { weeks } 12 \text { and } 24 \\
\text { >Ocrelizumab is more } \\
\text { effective than placebo }\end{array}$ & $\begin{array}{l}\text { - Annualized relapse rate } \\
\text { - Percentage of nonrelapsing patients } \\
\text { - Change in absolute T2 lesion volume } \\
\text { - Number of new gadolinium-positive T1 lesions between weeks } 4 \text { and } \\
24 \\
\text { - Number of gadolinium-positive T1 lesions between weeks } 4 \text { and } 24 \\
>\text { Ocrelizumab is more effective than placebo on all end points } \\
\text { examined with the exception of nonrelapsing patients and change in } \\
\text { absolute T2 lesion volume }\end{array}$ \\
\hline
\end{tabular}

\section{Phase 3 RMS}

Hauser et al. 2017

NEJM (OPERA I and II)

$\mathrm{n}=1,656$

$1: 1$ randomization to $600 \mathrm{mg}$ ocrelizumab IV every 6 months vs IFNß1a $30 \mu \mathrm{g}$ IM every wk for 86 wks

\section{- Annualized relapse rate $>$ Ocrelizumab is more effective than IFN beta-1a (reduction by $44 \%$ ) \\ - Time until onset of 6 months CDP (risk reduction of $40 \%$ confirmed at 12 and $24 \mathrm{wks}$ ) \\ - Number of gadolinium-positive T1 lesions \\ - Number of new and/or enlarged T2 lesions \\ - Percentage of patients with CDI \\ - Number of T1 lesions \\ - Change of MSFC compared with baseline \\ - Percentage change in brain volume \\ - Change in Short Form Health Survey-36 (SF-36) Physical Component \\ Summary (PCS) compared with baseline \\ - Percentage of patients with NEDA: \\ $>$ Ocrelizumab is more effective on all secondary end points except for OPERA I MSFC and SF-36 and is also more effective on all secondary end points except for CDI, and OPERA II percentage change in brain volume}

\section{Phase 3 PPMS}

Montalban et al. ${ }^{39} 2017$

NEJM (ORATORIO)

$\mathrm{n}=732$

Placebo or ocrelizumab $2 \times 300$ mg every 6

months for 120 wks
- Time to onset of sustained CDP of at least $12 \mathrm{wks}$ $>$ Ocrelizumab is more effective than placebo
- Time to onset of sustained CDP of at least 24 wks

- Percentage change of T25FW compared with baseline

- Percentage change in absolute T2 lesion volume compared with baseline

- Percentage change in brain volume

- Change in Physical Component Summary Score (PCS) and SF-36

Health Survey

- Percentage of patients with at least one adverse event:

$>$ Ocrelizumab is more effective in terms of time to onset of sustained CDP of at least 24 wks; percentage change in T25FW compared with baseline; percentage change in absolute $\mathrm{T} 2$ lesion volume compared with baseline; and percentage change in brain volume

Abbreviations: $\mathrm{CDI}=$ confirmed disability improvement; $\mathrm{CDP}=$ confirmed disability progression; IFN = interferon; IM = intramuscular; $\mathrm{MSFC}=\mathrm{MS}$ functional composite; NEDA = no evidence of disease activity; T25FW = Timed 25-Foot Walk.

\section{Ofatumumab}

Ofatumumab is a human monoclonal antibody that binds to a small-loop epitope on CD20. It depletes B cells through complement-dependent cytotoxicity and antibody-dependent cell-mediated cytotoxicity with great efficiency even when CD20 expression is low. ${ }^{32,43}$

A small phase 2 study examining ascending doses of 100, 300, and $700 \mathrm{mg}$ IV ofatumumab showed almost complete reduction in new MRI lesion activity. ${ }^{\mathrm{e} 4}$ These results prompted a larger-scale phase 2 dose-response study of subcutaneous ofatumumab in patients with relapsing-remitting MS. ${ }^{42}$ Two hundred thirty-two patients were randomized to receive 3,30 , or $60 \mathrm{mg}$ every 12 weeks, ofatumumab $60 \mathrm{mg}$ every 4 weeks, or placebo for 24 weeks. The primary end point was the number of cumulative new gadolinium-enhancing lesions on cerebral MRI. The cumulative number of gadolinium-enhancing lesions was reduced by 2 thirds in patients allocated to ofatumumab with a dose-dependent depletion of circulating CD19 B cells. Complete depletion apparently was not necessary for a treatment effect. Onset of action was observed by week 12. Furthermore, a conditioning dose added no benefit, and repletion occurred faster in all ofatumumab doses than previously reported with anti-CD20 therapy. Adverse events were mostly injection related and mild. ${ }^{43}$ An overview of further trials of subcutaneous ofatumumab in MS is provided in table 3.

Two pivotal ofatumumab phase 3 clinical trials enrolling participants with typical relapsing (94\%) and secondary progressive (5-6\%) MS were conducted ${ }^{\mathrm{e} 71, \mathrm{e} 72}$. The primary end point was annualized relapse rate, and pooled analysis was performed in a preplanned meta-analysis of disability worsening. Ofatumumab produced a relative risk reduction in the annualized relapse rate of between 50.5\% (ASCLEPIOS I) and $58.5 \%$ (ASCLEPIOS II) compared with teriflunomide ${ }^{\mathrm{e} 75, \mathrm{e} 76}$ (details in table 3 ). In the prespecified combined analysis of both trials, ofatumumab was superior to teriflunomide in cutting the risk of 3- and 6-month confirmed disability worsening by $34.4 . \%$ and $32.5 \%$, respectively. These clinical results were corroborated by MRI evaluation of metrics of disease activity and burden with one exception. No difference was noted for brain volume loss. Serum neurofilament light chain levels were lowered more markedly in the ofatumumab than the terilunomide group. Injection site reactions were common, but overall, ofatumumab was well tolerated. ${ }^{\mathrm{e} 76}$ 
Table 3 Overview of trials of subcutaneous ofatumumab in MS

\begin{tabular}{|c|c|c|}
\hline Trial & Patient population: relapsing MS & \\
\hline Phase 2 & $\begin{array}{l}\text { MIRROR } \\
\text { Dose-response study in patients with relapsing-remitting MS. } \\
\mathrm{n}=232 \text { patients were randomized to receive } 3,30 \text {, or } 60 \mathrm{mg} \\
\text { every } 12 \text { wks, } 60 \mathrm{mg} \text { every } 4 \text { wks, or placebo for } 24 \text { wks. The } \\
\text { primary end point was the number of cumulative new } \\
\text { gadolinium-enhancing lesions on cerebral MRI. } \\
\text { APOLITOS (OMB157G1301) } \\
\text { Japanese Registration Study } \\
\text { Ofatumumab versus placebo } \\
\text { 24-wks randomized double-blind placebo-controlled followed } \\
\text { by at least 24-wk open-label ofatumumab }\end{array}$ & $\begin{array}{l}\text { APLIOS (OMB157G2102) } \\
\text { prefilled syringe vs autoinjector, } 12 \text { wks }\end{array}$ \\
\hline $\begin{array}{l}\text { Phase } 3 \\
\text { Hauser et al., } 2020 \text { (NEJM) }\end{array}$ & $\begin{array}{l}\text { ASCLEPIOS I and II (OMB157G2301/OMB157G2301) } \\
\text { Ofatumumab } 20 \mathrm{mg} \text { vs teriflunomide } 14 \mathrm{mg} \text { daily plus placebo } \\
\text { SC plus oral placebo daily } \\
\text { ( } \mathrm{n}=927 \text { and } \mathrm{n}=955 \text {, respectively) (see text) }\end{array}$ & \\
\hline Phase 3b & $\begin{array}{l}\text { ALITHIOS (OMB157G2399) } \\
\text { Open-label long-term extension } \\
\text { Ofatumumab } 20 \text { mg every } 4 \text { wks }\end{array}$ & $\begin{array}{l}\text { ARTIOS Planned } \\
\text { Single-arm open-label study in patients transitioning } \\
\text { from dimethyl fumarate or fingolimod to ofatumumab, } \\
96 \text { wks }\end{array}$ \\
\hline
\end{tabular}

Abbreviation: SC = subcutaneous.

Ofatumumab in August 2020 received approval by the FDA for relapsing forms of MS (CIS, RRMS, and active SPMS) (e-table 2, links.lww.com/NXI/A346). The efficacy of ofatumumab offers patients an alternative administration route. They could self-inject.

This could obviate the need to attend a medical enter and avoid exposure to infective agents. This may arguably reduce utilization of healthcare resources. It remains to be seen whether the less profound depletion and faster repletion of B cells achieved with ofatumumab will also translate into a more favorable safety profile.

\section{Ongoing: ublituximab}

Ublituximab (TG-1101) is a novel glycoengineered anti-CD20 chimeric IgG1 monoclonal antibody. Potential advantages over currently available CD20 directed antibodies encompass induction of a higher degree of antibody-dependent cellular cytotoxicity, activity in low CD20 epitope expressing cells as is characteristic in rituximab resistance, binding to a novel epitope of CD20, and the shorter infusion time of 1 hour. Results of a phase 2 placebo-controlled trial, highlighting both efficacy and safety data, have recently been published. ${ }^{31} \mathrm{CD} 19$-positive cell depletion, the primary outcome, was achieved in $>95 \%$ and NEDA in $74 \%$ of patients receiving ublituximab. Infusionrelated reactions were the most common adverse events but mild in nature. Two phase 3 trials of ublituximab vs teriflunomide in patients with relapsing MS are currently ongoing.

\section{Atacicept, an inhibitor of B-cell differentiation that failed in MS}

Atacicept is a fully humanized recombinant fusion protein that interferes with B-cell differentiation, maturation, survival, and antibody production by binding to the cytokines BLyS (B-lymphocyte stimulator) and APRIL (also known as TNFSF13). ${ }^{\text {e77,e78 }}$ Animal studies suggested that its mode of action could produce therapeutic benefit in MS. ${ }^{\text {79 }}$ Unfortunately, a phase 2 trial revealed that this promising ${ }^{\mathrm{e} 80}$ mode of action leads rather to an exacerbation of disease, and the study had to be prematurely terminated. ${ }^{\mathrm{e} 1}$ This finding underscores the complex involvement of B cells in MS. ${ }^{\text {882 }}$ The failure of atacicept in MS may be associated with its shifting the balance of regulatory $\mathrm{B}$ cells ${ }^{\mathrm{e} 83}$ and memory B cells. ${ }^{\text {e8-e86 }}$ As a result, pathogenic memory B cells were stimulated. In addition, atacicept failed in optic neuritis, rheumatoid arthritis, and systemic lupus erythematosus. ${ }^{\text {87 }}$ Basic research on the B-cell survival factor suggests that the mode of modulation is crucial to achieve clinical efficacy. ${ }^{\text {e88 }}$

Perspectives: Bruton tyrosine kinase inhibitors Kinase inhibitors have recently appeared on the horizon as potential immunotherapeutics for MS. ${ }^{\text {e89 }}$ The implications of kinase inhibition and transition from bench to bedside in oncological diseases have been reviewed. ${ }^{\mathrm{e} 90-\mathrm{e} 92}$ The cytosolic Bruton tyrosine kinase is expressed exclusively on cells of the hematopoetic lineage and therefore affects the safety profile of this class of kinase inhibitors.

Evobrutinib, a selective, covalent, oral Bruton tyrosine kinase (BTK) inhibitor, blocks B-cell activation and cytokine release. ${ }^{\text {e93 }}$ The development of BTK inhibitors has generated promising agents. ${ }^{\text {e94 }}$ Ibrutinib was the first in class to be assessed in B-cell malignancy clinical trials. ${ }^{\text {e95 }}$ Preclinical characterization and phase 1 trials revealed that evobrutinib and branebrutinib are both well tolerated and potent inhibitors with high kinase selectivity. ${ }^{\text {e9-e99 }}$ The first kinase inhibitors are licensed for hematooncologic indications, including mantle cell lymphoma, chronic lymphocytic leukemia, and graft-versushost disease. ${ }^{\text {e100 }}$ The BTK inhibitor acalabrutinib has been granted breakthrough designation by the US Food and Drug Administration for the treatment of chronic lymphocytic leukemia. ${ }^{\text {e101 }}$ Thus, in malignancy, BTK inhibition is a promising 
therapeutic approach in B-cell diseases. ${ }^{\text {e102,e103 }}$ In MS, a phase 2 study of evobrutinib met its primary end point by significantly reducing the risk of developing gadolinium-enhancing lesions. ${ }^{42}$ It was well tolerated. A reversible increase in liver function tests was noted. Currently, studies with the BTK inhibitors BTKi ('168) (SAR442168) and GDC-0853 (fenebrutinib) have been completed, are ongoing, or about to get started. $^{\text {e104,e105 E-table 3, links.lww.com/NXI/A346, summa- }}$ rizes completed and planned phase 2 and 3 trials in MS.

Preclinical data from experimental autoimmune encephalomyelitis, EAE, suggest that BTK inhibitors may unfold their beneficial effect in MS via multiple mechanisms, i.e., modulation of the cytoplasmic tyrosine kinase and Tolllike receptor signaling. ${ }^{\text {e106 }}$ This may impair generation of (auto)antibodies and B-cell antigen-presenting function. Actions on myeloid cells including microglia may be particularly important given their presumed role in driving and maintaining an immunoinflammatory response with consequent neurodegeneration during the progressive stages of MS. As small molecules, BTK inhibitors may access the CNS easily and arrive in zones of subpial compartmentalized inflammation that are considered to significantly contribute to the pathobiology of progression. Given the medium effect size of, e.g., evobrutinib shown in phase 2 and the apparently benign safety profile, combination of oral BTK inhibitors with other high-efficacy drugs is being considered.

\section{Study funding}

No targeted funding reported.

\section{Disclosure}

J. Graf received conference and educational support from Biogen, Merck Serono, Sanofi Genzyme, and Grifols and a research fellowship from the Deutsche Forschungsgemeinschaft (project number 438899010). J. Mares reports no conflicts. M. Barnett has received institutional support for research, speaking, and/or participation in advisory boards for Biogen, Merck, Novartis, Roche, and Sanofi Genzyme; is a consulting neurologist for $\mathrm{RxMx}$; and is Research Director for the Sydney Neuroimaging Analysis Centre. O. Aktas received, with approval of the Rector of Heinrich-Heine University, grants from the German Research Foundation (DFG), the German Ministry for Education and Research (BMBF) as part of the German Competence Network Multiple Sclerosis (KKNMS; for NEMOS NationNMO-PAT FKZ 01GI1602B), and the Eugène Devic European Network (EU-FP7) and honoraria and travel/accommodation/meeting expenses from Almirall, Bayer, Biogen, MedImmune, Merck Serono, Novartis, Roche, Sanofi Genzyme, and Teva. P. Albrecht received, with approval of the Rector of Heinrich-Heine University and the CEO of University of Düsseldorf Hospital, personal fees, research grants, and nonfinancial support from Allergan, Biogen, Celgene, Ipsen, Merck Serono, Merz Pharmaceuticals, Novartis, and Roche and personal fees and nonfinancial support from Bayer HealthCare and Sanofi-Aventis/Genzyme, outside the submitted work. S.S. Zamvil is Deputy Editor of
Neurology, Neuroimmunology and Neuroinflammation and is an Associate Editor for Frontiers in Immunology and Frontiers in Neurology. He serves on the Advisory Committee for the American Congress on Treatment and Research in Multiple Sclerosis (ACTRIMS) and on the grant review committee for the National Multiple Sclerosis Society (NMSS). He has served as a consultant and received honoraria from Biogen Idec, EMD Serono, Genzyme, Novartis, Roche/Genentech, and Teva Pharmaceuticals, Inc., and has served on Data Safety Monitoring Boards for Lilly, BioMS, Teva, and Opexa Therapeutics. He receives research grant support from the NIH, NMSS, Weill Institute, Race to Erase MS, and the Maisin Foundation. H.-P. Hartung received honoraria for serving on steering and data monitoring committees, adboards, and speaking at scientific symposia from Bayer HealthCare, Biogen, Celgene BMS, Geneuro, MedImmune, Merck, Novartis, Roche, Teva, TG Therapeutics, and Viela Bio, with the approval of the Rector of Heinrich Heine University. Go to Neurology.org/NN for full disclosures.

\section{Publication history}

Received by Neurology: Neuroimmunology \& Neuroinflammation August 3, 2020. Accepted in final form September 11, 2020.

\begin{tabular}{|c|c|c|}
\hline Name & Location & Contribution \\
\hline $\begin{array}{l}\text { Jonas Graf, } \\
\text { MD }\end{array}$ & $\begin{array}{l}\text { Heinrich Heine University, } \\
\text { Düsseldorf, Germany }\end{array}$ & $\begin{array}{l}\text { Review concept/design } \\
\text { and drafting of the } \\
\text { manuscript }\end{array}$ \\
\hline $\begin{array}{l}\text { Jan Mares, } \\
\text { MD }\end{array}$ & $\begin{array}{l}\text { Palacky University, } \\
\text { Olomouc, Czech Republic }\end{array}$ & $\begin{array}{l}\text { Drafting and revision of } \\
\text { the manuscript }\end{array}$ \\
\hline $\begin{array}{l}\text { Michael } \\
\text { Barnett, MD, } \\
\text { PhD }\end{array}$ & $\begin{array}{l}\text { University of Sydney, } \\
\text { Australia }\end{array}$ & $\begin{array}{l}\text { Drafting and revision of } \\
\text { the manuscript }\end{array}$ \\
\hline $\begin{array}{l}\text { Orhan Aktas, } \\
\text { MD }\end{array}$ & $\begin{array}{l}\text { Heinrich Heine University, } \\
\text { Düsseldorf, Germany }\end{array}$ & $\begin{array}{l}\text { Drafting and revision of } \\
\text { the manuscript }\end{array}$ \\
\hline $\begin{array}{l}\text { Philipp } \\
\text { Albrecht, MD }\end{array}$ & $\begin{array}{l}\text { Heinrich Heine University, } \\
\text { Düsseldorf, Germany }\end{array}$ & $\begin{array}{l}\text { Revision of the } \\
\text { manuscript }\end{array}$ \\
\hline $\begin{array}{l}\text { Scott S. } \\
\text { Zamvil, MD, } \\
\text { PhD }\end{array}$ & UCSF, San Francisco, USA & $\begin{array}{l}\text { Revision of the } \\
\text { manuscript }\end{array}$ \\
\hline $\begin{array}{l}\text { Hans-Peter } \\
\text { Hartung, MD, } \\
\text { PhD, FRCP }\end{array}$ & $\begin{array}{l}\text { Heinrich Heine University, } \\
\text { Düsseldorf, Germany, and } \\
\text { University of Sydney, } \\
\text { Australia }\end{array}$ & $\begin{array}{l}\text { Review concept/design } \\
\text { and drafting and revision } \\
\text { of the manuscript }\end{array}$ \\
\hline
\end{tabular}

\section{References}

1. Thompson AJ, Baranzini SE, Geurts J, Hemmer B, Ciccarelli O. Multiple sclerosis. Lancet 2018;391:1622-1636.

2. Lublin FD, Coetzee T, Cohen JA, Marrie RA, Thompson AJ. The 2013 clinical course descriptors for multiple sclerosis: a clarification. Neurology 2020:94:1088-1092.

3. Lublin FD, Reingold SC, Cohen JA, et al. Defining the clinical course of multiple sclerosis: the 2013 revisions. Neurology 2014;83:278-286.

4. Lublin FD. New multiple sclerosis phenotypic classification. Eur Neurol 2014;72 (suppl 1):1-5.

5. Kinzel S, Weber MS. B cell-directed therapeutics in multiple sclerosis: rationale and clinical evidence. CNS Drugs 2016;30:1137-1148.

6. Gingele S, Skripuletz T, Jacobs R. Role of CD20+ T cells in multiple sclerosis: implications for treatment with ocrelizumab. Neural Regen Res 2020;15: 663-664. 
7. Wu Y, Zhong L, Geng J. Neuromyelitis optica spectrum disorder: pathogenesis, treatment, and experimental models. Mult Scler Relat Disord 2019;27:412-418.

8. Kawachi I, Lassmann H. Neurodegeneration in multiple sclerosis and neuromyelitis optica. J Neurol Neurosurg Psychiatry 2017;88:137-145

9. Mader S, Kümpfel T, Meinl E. Novel insights into pathophysiology and therapeutic possibilities reveal further differences between AQP4-IgG- and MOG-IgG-associated diseases. Curr Opin Neurol 2020;33:362-371.

10. Zamvil SS, Slavin AJ. Does MOG Ig-positive AQP4-seronegative opticospinal inflammatory disease justify a diagnosis of NMO spectrum disorder? Neurol Neuroimmunol Neuroinflamm 2015;2:e62.

11. Jarius S, Ruprecht K, Kleiter I, et al. MOG-IgG in NMO and related disorders: a multicenter study of 50 patients. Part 2: epidemiology, clinical presentation, radiological and laboratory features, treatment responses, and long-term outcome. J Neuroinflammation 2016;13:280.

12. Papathanasiou A, Tanasescu R, Davis J, et al. MOG-IgG-associated demyelination: focus on atypical features, brain histopathology and concomitant autoimmunity. J Neurol 2020;267:359-368.

13. Höftberger R, Guo Y, Flanagan EP, et al. The pathology of central nervous system inflammatory demyelinating disease accompanying myelin oligodendrocyte glycoprotein autoantibody. Acta Neuropathol 2020;139:875-892.

14. Fujihara K, Cook LJ. Neuromyelitis optica spectrum disorders and myelin oligodendrocyte glycoprotein antibody-associated disease: current topics. Curr Opin Neurol 2020;33:300-308.

15. Jurynczyk M, Messina S, Woodhall MR, et al. Clinical presentation and prognosis in MOG-antibody disease: a UK study. Brain 2017;140:3128-3138.

16. Takai Y, Misu T, Kaneko K, et al. Myelin oligodendrocyte glycoprotein antibodyassociated disease: an immunopathological study. Brain 2020;143:1431-1446.

17. Hor JY, Asgari N, Nakashima I, et al. Epidemiology of neuromyelitis optica spectrum disorder and its prevalence and incidence worldwide. Front Neurol 2020;11 501.

18. Sabatino JJ, Pröbstel A-K, Zamvil SS. B cells in autoimmune and neurodegenerative central nervous system diseases. Nat Rev Neurosci 2019;20:728-745.

19. Sabatino JJ, Pröbstel A-K, Zamvil SS. Publisher Correction: B cells in autoimmune and neurodegenerative central nervous system diseases. Nat Rev Neurosci 2020, 21:56.

20. Sellebjerg F, Blinkenberg M, Sorensen PS. Anti-CD20 monoclonal antibodies for relapsing and progressive multiple sclerosis. CNS Drugs 2020;34:269-280.

21. Kim S-H, Hyun J-W, Kim HJ. Individualized B cell-targeting therapy for neuromyelitis optica spectrum disorder. Neurochem Int 2019;130:104347.

22. Stüve O, Cepok S, Elias B, et al. Clinical stabilization and effective B-lymphocyte depletion in the cerebrospinal fluid and peripheral blood of a patient with fulminant relapsing-remitting multiple sclerosis. Arch Neurol 2005;62:1620-1623.

23. Monson NL, Cravens PD, Frohman EM, Hawker K, Racke MK. Effect of rituximab on the peripheral blood and cerebrospinal fluid B cells in patients with primary progressive multiple sclerosis. Arch Neurol 2005;62:258-264.

24. Cross AH, Stark JL, Lauber J, Ramsbottom MJ, Lyons J-A. Rituximab reduces B cells and $\mathrm{T}$ cells in cerebrospinal fluid of multiple sclerosis patients. J Neuroimmunol 2006, 180:63-70.

25. Leussink VI, Lehmann HC, Meyer zu Hörste G, Hartung H-P, Stüve O, Kieseier BC. Rituximab induces clinical stabilization in a patient with fulminant multiple sclerosis not responding to natalizumab. Evidence for disease heterogeneity. J Neurol 2008; 255:1436-1438.

26. Stüve O, Leussink VI, Fröhlich R, et al. Long-term B-lymphocyte depletion with rituximab in patients with relapsing-remitting multiple sclerosis. Arch Neurol 2009; 66:259-261.

27. Cree BAC, Lamb S, Morgan K, Chen A, Waubant E, Genain C. An open label study of the effects of rituximab in neuromyelitis optica. Neurology 2005;64:1270-1272.

28. Jacob A, Weinshenker BG, Violich I, et al. Treatment of neuromyelitis optica with rituximab: retrospective analysis of 25 patients. Arch Neurol 2008;65:1443-1448.

29. Pellkofer HL, Krumbholz M, Berthele A, et al. Long-term follow-up of patients with neuromyelitis optica after repeated therapy with rituximab. Neurology 2011;76: 1310-1315.

30. Beers SA, Chan CHT, French RR, Cragg MS, Glennie MJ. CD20 as a target for therapeutic type I and II monoclonal antibodies. Semin Hematol 2010;47:107-114.

31. Fox E, Lovett-Racke AE, Gormley M, et al. A phase 2 multicenter study of ublituximab, a novel glycoengineered anti-CD20 monoclonal antibody, in patients with relapsing forms of multiple sclerosis. Mult Scler 2020:1352458520918375.
32. Teeling JL, Mackus WJM, Wiegman LJJM, et al. The biological activity of human CD20 monoclonal antibodies is linked to unique epitopes on CD20. J Immunol 2006; 177:362-371.

33. Rougé L, Chiang N, Steffek M, et al. Structure of CD20 in complex with the therapeutic monoclonal antibody rituximab. Science 2020;367:1224-1230.

34. Klein C, Lammens A, Schäfer W, et al. Epitope interactions of monoclonal antibodies targeting CD20 and their relationship to functional properties. MAbs 2013;5:22-33.

35. Niederfellner G, Lammens A, Mundigl O, et al. Epitope characterization and crystal structure of GA101 provide insights into the molecular basis for type I/II distinction of CD20 antibodies. Blood 2011;118:358-367.

36. Kumar A, Planchais C, Fronzes R, Mouquet H, Reyes N. Binding mechanisms of therapeutic antibodies to human CD20. Science 2020;369:793-799.

37. Bondza S, Broeke Tten, Nestor M, Leusen JHW, Buijs J. Bivalent binding on cells varies between anti-CD20 antibodies and is dose-dependent. MAbs 2020;12:1792673.

38. Hawker K, O'Connor P, Freedman MS, et al. Rituximab in patients with primary progressive multiple sclerosis: results of a randomized double-blind placebocontrolled multicenter trial. Ann Neurol 2009;66:460-471.

39. Montalban X, Hauser SL, Kappos L, et al. Ocrelizumab versus placebo in primary progressive multiple sclerosis. N Engl J Med 2017;376:209-220.

40. Barnas JL, Looney RJ, Anolik JH. B cell targeted therapies in autoimmune disease. Curr Opin Immunol 2019;61:92-99.

41. Molnarfi N, Schulze-Topphoff U, Weber MS, et al. MHC class II-dependent B cell APC function is required for induction of CNS autoimmunity independent of myelinspecific antibodies. J Exp Med. 2013;210:2921-2937.

42. Montalban X, Arnold DL, Weber MS, et al. Placebo-controlled trial of an oral BTK inhibitor in multiple sclerosis. N Engl J Med 2019;380:2406-2417.

43. Bar-Or A, Grove RA, Austin DJ, et al. Subcutaneous ofatumumab in patients with relapsing-remitting multiple sclerosis: the MIRROR study. Neurology 2018;90: e1805-e1814.

44. Freeman CL, Sehn LH. A tale of two antibodies: obinutuzumab versus rituximab. Br J Haematol 2018;182:29-45.

45. Svenningsson A, Bergman J, Dring A, et al. Rapid depletion of B lymphocytes by ultralow-dose rituximab delivered intrathecally. Neurol Neuroimmunol Neuroinflamm 2015;2:e79.

46. Komori M, Lin YC, Cortese I, et al. Insufficient disease inhibition by intrathecal rituximab in progressive multiple sclerosis. Ann Clin Transl Neurol 2016;3:166-179.

47. Li R, Patterson KR, Bar-Or A. Reassessing B cell contributions in multiple sclerosis. Nat Immunol 2018;19:696-707.

48. Bar-Or A, Fawaz L, Fan B, et al. Abnormal B-cell cytokine responses a trigger of T-cellmediated disease in MS? Ann Neurol 2010;67:452-461.

49. Weber MS, Prod'homme T, Patarroyo JC, et al. B-cell activation influences T-cell polarization and outcome of anti-CD20 B-cell depletion in central nervous system autoimmunity. Ann Neurol 2010;68:369-383.

50. Rahmanzadeh R, Weber MS, Brück W, Navardi S, Sahraian MA. B cells in multiple sclerosis therapy-A comprehensive review. Acta Neurol Scand 2018;137:544-556.

51. Sospedra M. B cells in multiple sclerosis. Curr Opin Neurol 2018;31:256-262.

52. Baecher-Allan C, Kaskow BJ, Weiner HL. Multiple sclerosis: mechanisms and immunotherapy. Neuron 2018;97:742-768.

53. Greenfield AL, Hauser SL. B-cell therapy for multiple sclerosis: entering an era. Ann Neurol 2018;83:13-26.

54. Rommer PS, Milo R, Han MH, et al. Immunological aspects of approved MS therapeutics. Front Immunol 2019;10:1564.

55. Comi G, Bar-Or A, Lassmann H, et al. The role of B cells in multiple Sclerosis and related disorders. Ann Neurol 2020 Oct 9. doi: 10.1002/ana.2592

56. Ransohoff RM. Immune-cell crosstalk in multiple sclerosis. Nature 2018;563:194-195.

57. Márquez AC, Horwitz MS. The role of latently infected B cells in CNS autoimmunity. Front Immunol 2015;6:544.

58. Bar-Or A, Pender MP, Khanna R, et al. Epstein-barr virus in multiple sclerosis: theory and emerging immunotherapies. Trends Mol Med 2020;26:296-310.

59. Anthony DC, Dickens AM, Seneca N, et al. Anti-CD20 inhibits T cell-mediated pathology and microgliosis in the rat brain. Ann Clin Transl Neurol 2014;1:659-669.

60. Chen D, Ireland SJ, Remington G, et al. CD40-Mediated NF- $\mathrm{kB}$ activation in B cells is increased in multiple sclerosis and modulated by therapeutics. J Immunol 2016;197: $4257-4265$.

Data available from Dryad. Additional references (e1-e103) available at: links.lww. com/NXI/A354. 


\section{Neurology \\ Neuroimmunology \& Neuroinflammation}

Targeting B Cells to Modify MS, NMOSD, and MOGAD: Part 1

Jonas Graf, Jan Mares, Michael Barnett, et al.

Neurol Neuroimmunol Neuroinflamm 2021;8;

DOI 10.1212/NXI.0000000000000918

This information is current as of December 16, 2020

\section{Updated Information \& Services}

References

Permissions \& Licensing

Reprints including high resolution figures, can be found at:

http://nn.neurology.org/content/8/1/e918.full.html

This article cites 59 articles, 9 of which you can access for free at: http://nn.neurology.org/content/8/1/e918.full.html\#\#ref-list-1

Information about reproducing this article in parts (figures,tables) or in its entirety can be found online at:

http://nn.neurology.org/misc/about.xhtml\#permissions

Information about ordering reprints can be found online: http://nn.neurology.org/misc/addir.xhtml\#reprintsus

Neurol Neuroimmunol Neuroinflamm is an official journal of the American Academy of Neurology.

Published since April 2014, it is an open-access, online-only, continuous publication journal. Copyright

Copyright (C) 2020 The Author(s). Published by Wolters Kluwer Health, Inc. on behalf of the American

Academy of Neurology.. All rights reserved. Online ISSN: 2332-7812.

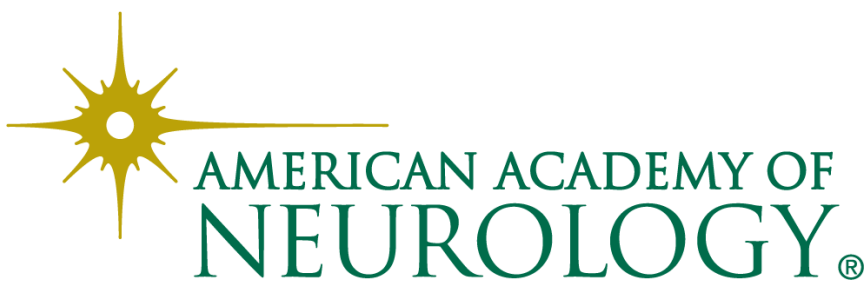

